\title{
Are mesenchymal stromal cells immune cells?
}

\author{
Martin J Hoogduijn
}

\begin{abstract}
Mesenchymal stromal cells (MSCs) are considered to be promising agents for the treatment of immunological disease. Although originally identified as precursor cells for mesenchymal lineages, in vitro studies have demonstrated that MSCs possess diverse immune regulatory capacities. Pre-clinical models have shown beneficial effects of MSCs in multiple immunological diseases and a number of phase 1/2 clinical trials carried out so far have reported signs of immune modulation after MSC infusion. These data indicate that MSCs play a central role in the immune response. This raises the academic question whether MSCs are immune cells or whether they are tissue precursor cells with immunoregulatory capacity. Correct understanding of the immunological properties and origin of MSCS will aid in the appropriate and safe use of the cells for clinical therapy. In this review the whole spectrum of immunological properties of MSCs is discussed with the aim of determining the position of MSCs in the immune system.
\end{abstract}

\section{Introduction}

Mesenchymal stromal cells (MSCs) were originally identified as precursors for cells of the osteogenic lineage [1]. They were later discovered to be able to differentiate also into the chondrogenic, adipogenic and myogenic lineages [2]. Within the scientific community there is some controversy about the naming and precise definition of MSCs. The term 'mesenchymal stromal cell' is used in parallel with 'mesenchymal stem cell' and 'multipotent mesenchymal stromal cell'. MSCs are in fact a heterogeneous population of cells that express CD73, CD90 and CD105 and lack the haematopoietic lineage markers CD45, CD34, CD11c, CD14, CD19, CD79A and HLA-DR [3]. This immunophenotype, however, covers various subsets of MSCs with different phenotypes and different functions $[4,5]$. Cell isolation procedures can, therefore, affect the cellular composition of MSC cultures. Culture conditions can have a further impact on the phenotype and function of MSCs [6]. This may affect study outcomes. Therefore, some care should be taken in comparing the results of studies using different MSC isolation and culture procedures.

In the bone marrow, MSCs have a supportive function for the haematopoietic system and provide a niche for haematopoietic progenitor cells to mature. The presence of MSCs is not limited, however, to the bone marrow and in other tissues, such as adipose tissue, muscle and multiple organs, they provide support for tissue cells by producing growth factors and matrix proteins. In addition to their differentiation and tissue supportive functions, MSCs have a well-established immune modulatory function. Several in vitro studies have demonstrated that MSCs are able to effectively inhibit $\mathrm{T}$ lymphocyte $[7,8]$ and natural killer (NK) lymphocyte [9] proliferation, impair antibody production by B cells [10], and inhibit the maturation and function of dendritic cells [11]. Studies in animal models have shown that MSCs can reduce disease progression and/or severity of various immune diseases such as collagen-induced arthritis [12], experimental autoimmune encephalomyelitis [13], experimental colitis and sepsis [14]. It is believed that MSCs mediate their beneficial effects by modulating the immune system, although the exact mechanisms of immunomodulation by MSCs in vivo are not clear. Even though there is abundant evidence that MSCs modulate immune responses by interacting with cells of the immune system, the question is whether MSCs themselves should be perceived as true immune cells. Do MSCs exercise immune functions like immune cells do and what is their response to pathogens? In this review, the various immunological roles of MSCs are discussed, culminating in a conclusion on the position of MSCs in the immune system. 


\section{Immunological properties of mesenchymal stromal cells} Interaction with immune cells

MSCs interact with cells of the immune system via a plethora of mechanisms. They secrete anti-inflammatory factors such as transforming growth factor $\beta$ (TGF- $\beta$ ), hepatocyte growth factor (HGF) and prostaglandin-E2 (PGE-2) [7,8], and they express cell surface molecules with immunosuppressive properties such as programmed death ligand 1 (PD-L1) and Fas ligand $[15,16]$, via which they directly target immune cells and inhibit their activation and function. MSCs furthermore attract immune cells by secreting a broad mixture of chemokines. In particular, the neutrophil chemo-attractant interleukin (IL)-8 and the monocyteattractant CCL2 are secreted in high amounts by MSCs [17]. Chemokine secretion by MSCs may act in a dual way to modulate the immune response. Reactive immune cells will be attracted and exert their immunological function, but at the same time they may be targeted by MSCs and inhibited in their function. There is evidence that MSCs bind activated immune cells [18], potentially to keep them at a close distance to enhance the effect of their immunosuppressive actions. The immunoregulatory effects of MSCs are not only directed directly against efxfector immune cells. MSCs do not themselves produce the anti-inflammatory cytokine IL-10, but they induce other cell types to do this [19]. Via the secretion of TGF- $\beta$ and other factors MSCs also promote the induction of regulatory $\mathrm{T}$ cells [20], regulatory macrophages [21] and regulatory B cells [22], and in this way pass on their immunosuppressive effects to other cell types that exert different mechanisms of immune suppression. A schematic overview of the interactions between MSCs and immune cells is depicted in Figure 1.

\section{Metabolic control of the immune system}

In addition to the well described mechanisms of immune modulation via cytokines, chemokines and inhibitory costimulation molecules, MSCs are actively involved in the metabolic control of the immune system. MSCs can be induced to express the enzyme indoleamine 2,3-dioxygenase (IDO), which has a potent capacity to inhibit lymphocyte proliferation by metabolising L-tryptophan to L-kynurenine [23]. Reduced levels of L-tryptophan suppress lymphocyte proliferation and, simultaneously, high levels of Lkynurenine impose a block on proliferation as well. Furthermore, MSCs strongly and constitutively express CD73 [3], which acts in concordance with CD39 on regulatory $\mathrm{T}$ cells to metabolise ATP to adenosine, thereby taking away the inflammation-promoting effect of ATP [24]. Metabolic control of the immune response also occurs through other mechanisms, such as L-arginine metabolism, which is employed by myeloid cells to inhibit lymphocyte activities [25]. It is unknown whether MSCs make use of this pathway to regulate immune cells.

\section{Adaptation to inflammatory conditions}

MSCs can be considered as genuine regulators of the immune system because they adapt their immunoregulatory properties to the local immunological milieu. MSCs sense inflammation and in response to pro-inflammatory cytokines, in particular interferon- $\gamma$ and tumour necrosis factor (TNF)- $\alpha$, they change their immunological role. In the absence of inflammation, MSCs promote the survival of T lymphocytes [26] and can even stimulate their proliferation, partly via IL-6-dependent mechanisms [27]. MSCs have recently been identified as producers of IL-7 [28], which stimulates the differentiation of haematopoietic cells into lymphoid cells but also promotes the proliferation of lymphocytes. Once placed under immune activating conditions, MSCs upregulate the expression of IDO, HGF, PD-L1, TNF-stimulated gene 6 protein and PGE2-producing cyclooxygenase 2 [29] as part of immunological negative feedback loops [30]. MSCs adapted to inflammatory conditions will inhibit immune cell activation and proliferation [31] and increase their regulatory T cell-inducing capacity [32]. Even though the expression of pro-inflammatory factors such as IL-6, IL-7 and several chemokines by MSCs is also increased under inflammatory conditions, the immunosuppressive effects of MSCs prevail under these conditions. MSCs thus play a central role in maintaining immune homeostasis by interacting with immune cells via cytokines, chemokines, cell surface molecules and metabolic pathways. The question is whether this is sufficient to qualify MSCs as immune cells. Strictly speaking, an immune cell protects organisms against pathogens, cleans up cell debris, and removes diseased cells. The MSC functions described above steer the activities of the immune system but do not by themselves represent core immune functions. Do MSCs possess these properties?

\section{Role of mesenchymal stromal cells in immune defence}

Immune cell effector functions

Immune cells fight diseased cells and pathogens by cytotoxic activity, antibody production, and phagocytosis. MSCs do not express granzymes or perforins and do not produce antibodies and are not, therefore, capable of cytotoxic activity or participation in the humoral defence. There is some evidence, however, that MSCs possess phagocytic properties. It was shown that MSCs can phagocytise apoptotic cells, which as a result enhances their osteogenic differentiation capacity [33]. MSCs that phagocytised apoptotic cells increased chemokine expression and induced Th17 cells, suggesting that phagocytosis leads to an immune-activating response in MSCs. More data on the phagocytic activity of MSCs are not available at present, which leaves their role as a phagocytic cell unclear. Overall, there is no overwhelming evidence that MSCs act as effector cells in the immune system. 


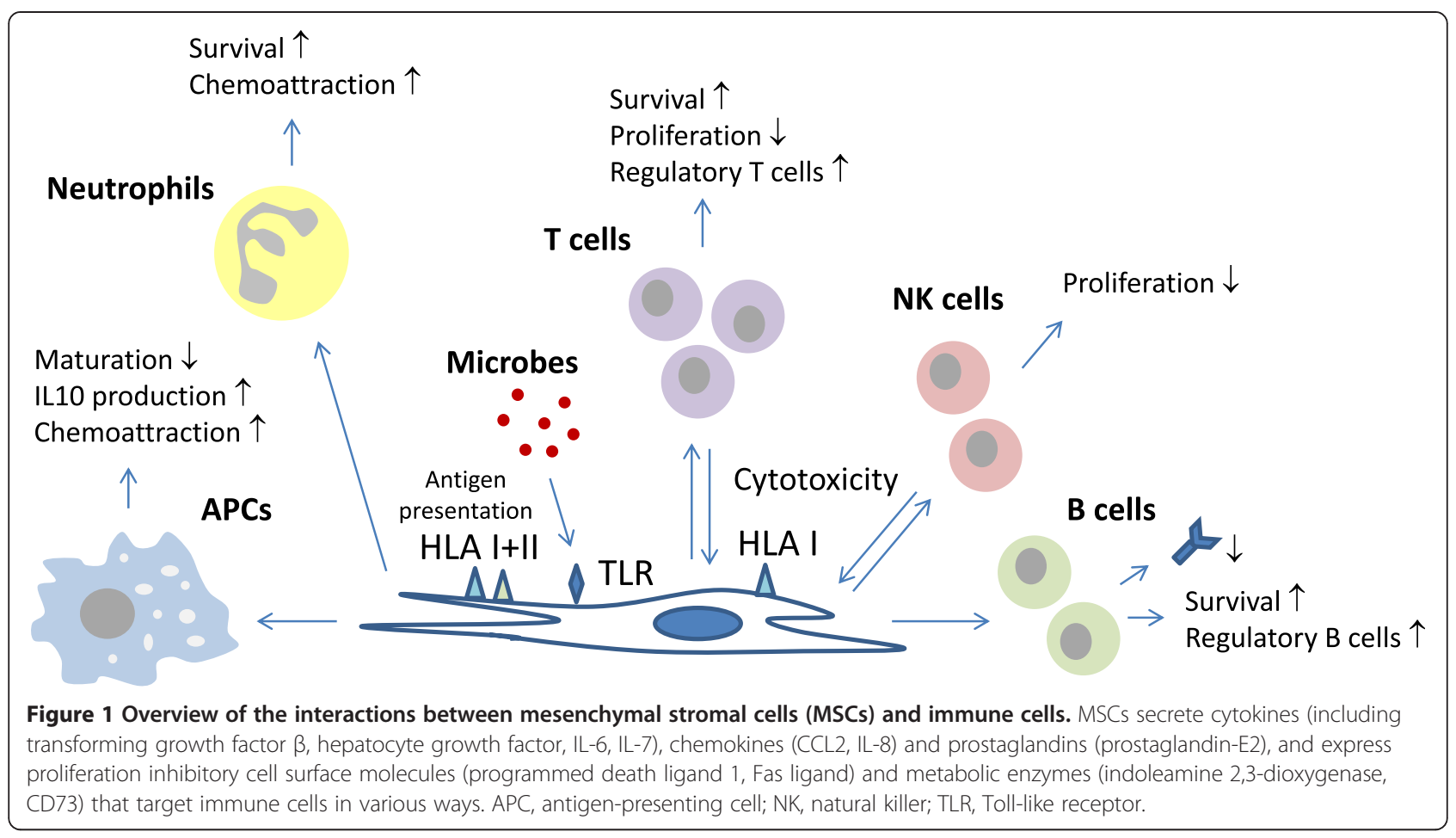

\section{Antigen presentation}

Whereas MSCs may not have immune cell effector functions, they can play a role in the initiation of immune responses. MSCs have the capacity, like all nucleated cells, to present antigen via major histocompatibility complex (MHC) class I molecules, which are constitutively expressed on MSCs. Antigens presented via MHC class I are endogenous antigens and their presentation serves the recognition of pathogen-infected or transformed cells by $\mathrm{CD}^{+}$cytotoxic cells. Under inflammatory conditions, MSCs also express MHC class II and thereby gain the capacity to present exogenous antigens to $\mathrm{T}$ cells $[34,35]$, a property shared by professional antigenpresenting cells such as dendritic cells and macrophages. Interferon- $\gamma$-stimulated MSCs furthermore possess $\mathrm{MHC}$ class II-mediated antigen processing capacity [36]. Under inflammatory conditions MSCs can thus present antigens from their environment and induce adaptive immune responses by activation of $\mathrm{CD}^{+} \mathrm{T}$ cells. In addition, MSCs can cross-present antigens via their MHC class I molecules and process antigen via proteasome- and transporter molecule-dependent mechanisms [37]. Via this route MSCs can initiate CD8 ${ }^{+} \mathrm{T}$-cell responses to exogenous antigens. Although the ability to process and present antigens would appear to be a typical immune cell function, is it not unique to immune cells. Endothelial cells and fibroblasts, like MSCs, upregulate MHC class II under inflammatory conditions, and under these conditions they are potent stimulators of $\mathrm{CD}^{+}{ }^{+} \mathrm{T}$-cell responses [38]. Endothelial cells furthermore have the capacity to cross-present antigens via MHC class I [39]. Antigen presentation under inflammatory conditions is thus a capacity shared by different types of tissue cells.

\section{Response to pathogens}

MSCs do not possess receptors that recognise specific antigens, such as cells of the adaptive immune system do via $\mathrm{T}$ - and B-cell receptors. Recognition of antigen by innate immune cells is mediated via a broad range of pattern recognition receptors. MSCs express certain pattern recognition receptors, including NOD-like receptors [40] and Toll-like receptors (TLRs) [41]. Inflammatory conditions affect the expression of TLRs on MSCs [42] and TLR activation may lead to an inhibition of the immunosuppressive effects of MSCs, allowing T-cell responses to build up [43], although there is also evidence that the immunosuppressive effects of MSCs are increased by TLR activation [44]. Via their pattern recognition receptors MSCs recognise microbes and upon MSC-microbe association they increase the expression of immunomodulatory genes such as IL-6, IL-8 and cyclooxygenase-2 [45]. As a result, the capacity of MSCs to inhibit T-cell proliferation is enhanced, which could serve as a negative feedback loop to protect against collateral damage of strong immune responses against microbes. MSCs furthermore exert direct anti-microbial effects, as demonstrated in Escherichia coli- 
injured human lungs. MSCs were shown to phagocytise bacteria and secrete keratinocyte growth factor, which induces monocytes to support the anti-microbial effect of MSCs [46]. MSCs do thus participate in the defence against microbial threats.

\section{Migration to sites of inflammation}

Immune cells migrate to sites of infection/inflammation in response to chemokine attraction. Upon activation they upregulate adhesion molecules and rolling and invasion machinery and stick to the endothelium and migrate in between endothelial cells and tissue cells to the source of the chemokine production. MSCs also express chemokine receptors and migrate in vitro in response to chemotactic stimulation. This property is enhanced under inflammatory conditions [47]. There is controversy about the migratory ability of in vivo administered MSCs, but for a comparison of the migratory properties of MSCs with immune cells the migration of endogenous MSCs should be discussed. Whereas MSCs have been detected in the circulation in animal models, there is little evidence for the presence of MSCs in the human circulation [48], except for under conditions where the MSC niche is disrupted, such as in trauma patients $[49,50]$. A study has demonstrated that human MSCs can egress from adipose tissue to migrate to lymph nodes [51], suggesting that MSCs may avoid the blood stream as a means of transportation and instead use the lymphatic system. Via the lymphatic system MSCs would not, however, reach sites of tissue inflammation. In contrast to neutrophils, macrophages and lymphocytes, the need for MSC recruitment from distant sites to inflamed tissue may not be essential as MSCs are already present in all tissues. MSCs may be recruited locally to increase their presence at inflamed sites.

MSCs thus certainly play a role in the immune defence, but their tasks are not as specialised as those of other types of immune cells. MSCs rather support various aspects of the immune response.

\section{The origin of mesenchymal stromal cells Mesenchymal origin}

During embryonic development MSCs are derived from the mesodermal germ layer; the mesoderm forms the connective tissue and the haematopoietic system. Whereas all traditional immune cells are of haematopoietic origin, the developmental origin of MSCs is not entirely clear and a matter of debate. The hypothesis that MSCs are of bone marrow stromal origin and migrate from there to peripheral tissues to occupy their place as regenerative and immunomodulatory cells during adulthood is outdated by data showing that MSCs of recipient origin are not found in transplanted organs even many years after transplantation [52] and the absence of MSCs in the circulation of healthy individuals and patients with severe organ injury [50]. The discovery in multiple organs of cells around blood vessels that lack haematopoietic, endothelial, and myogenic cell markers but possess multi-lineage differentiation capacity and express MSC markers has suggested that MSCs are of perivascular origin [53]. More recently, it was demonstrated that tooth MSCs are derived from peripheral nerve-associated glial cells [54]. These results suggest that MSCs are distributed throughout the body during development and reside in their specific niche during adulthood from where they act locally to mediate regenerative and immunomodulatory processes.

\section{Haematopoietic origin?}

Although the non-haematological origin of MSCs is generally accepted, data suggest that the distinction between haematopoietic and non-haematopoietic cells may not be as sharp as commonly believed. A suggestion for this may arise from the fact that adipose tissue-derived MSCs express the haematopoietic stem cell marker CD34. Furthermore, elegant experiments carried out a decade ago demonstrated that the transplantation of single green fluorescent protein (GFP)-expressing haematopoietic stem cells in mice led to the generation of GFP-positive microglial and perivascular cells [55], cells that are members of the MSC family. This would indicate that primitive haematopoietic progenitor cells have the capacity to differentiate into mesenchymal lineages. In further support of the relationship of MSCs with the haematopoietic lineage are the similarities that exist between fibroblasts and macrophages, as reviewed by Ogawa and colleagues [56]. Fibroblasts are derived from MSCs and like their precursor cells they can adapt immunoregulatory properties and become activated to secrete growth factors in case of tissue injury. Macrophages in their turn can adapt similar regenerative properties and can home to injured tissue where they stimulate repair processes [57]. In contrast to the idea that MSCs are of haematopoietic origin, it is well known that MSCs can be locally formed in tissue in a process called epithelial to mesenchymal transition in which epithelial cells give rise to MSCs in response to injury. Despite the so far contrasting and insufficient data on the classification of MSCs, the view that MSCs are of nonhaematopoietic origin is currently the most widely accepted. In this view, MSCs are thus of a different lineage than classical immune cells.

\section{Immunomodulatory therapy with mesenchymal stromal cells \\ Infusion of mesenchymal stromal cells}

The use of MSCs for immunomodulatory therapy for a variety of immunological disorders is intensively studied. Phase $1 / 2$ clinical trials have been performed in graft versus host disease [58], organ transplantation [59,60], and 
multiple types of autoimmune diseases, including inflammatory bowel disease $[61,62]$, systemic lupus erythematosus $[63,64]$ and multiple sclerosis [65]. Some of the studies showed amelioration of disease severity, albeit the studies were non-controlled. The use of MSCs for rheumatoid arthritis has been examined in disease models by multiple research groups [66] and a clinical study in 172 rheumatoid arthritis patients demonstrated that intravenous infusion of allogeneic MSCs was feasible and safe and induced a significant disease remission [67]. A placebo-controlled study in chronic obstructive pulmonary disease demonstrated that MSC therapy lowered C-reactive protein levels, but did not affect disease indicators [68]. Although the efficacy of MSC immunotherapy remains to be demonstrated in larger placebo-controlled trials, in several of the studies there were indications that the infusion of MSCs leads to immunomodulatory effects. Do these effects prove that MSCs are immune cells? If one looks in detail at the immunological effects that are induced by the infusion of MSCs, it can be observed that MSCs induce small inflammatory responses shortly after infusion [69], whereas it is likely that the immunosuppressive effects of MSCs take longer to occur. MSCs that are administered via the intravenous route are, however, short-lived and the large majority of them disappear after 24 hours [70]. It is thus likely that the immunosuppressive effects of MSC treatment are mediated by other cell types and there is indeed accumulating evidence that MSCs induce regulatory T cells [71,72]. Thus, MSCs themselves may not be active as immunoregulators after administration, but the regulatory immune cells that they induce may mediate these effects. In this sense, MSCs do not fit the definition of an immune cell, but should rather been seen as coordinators of the immune system.

Basically all clinical studies of the immunomodulatory effect of MSCs have been performed after intravenous infusion of MSCs. Intravenous infusion is the easiest and therefore most commonly used route of administration of MSCs, but it is possible that MSCs that are administered via other routes act via different modes of action. When MSCs are administered intramuscularly or are delivered via the arterial route to tissues of interest, they localise close to or even within sites of inflammation and they may interact with immune cells in a more direct way and may survive for a longer time. Whether MSCs administered into inflammatory sites act more like true immunoregulatory cells needs to be studied in more detail.

\section{Immunogenicity of mesenchymal stromal cells}

In contrast to immune cells, MSCs express low levels of HLA class I and co-stimulatory molecules CD80 and CD86 and are therefore low immunogenic. Like other cells, MSCs do, however, induce allogeneic immune cell responses, as demonstrated by the lysis of MSCs by
HLA class I mismatched memory $\mathrm{CD}^{+} \mathrm{T}$ cells [73]. In this sense MSCs do not behave differently from immune cells. Different from immune cells, culture-expanded MSCs are also susceptible to lysis by autologous IL-2activated NK cells [9]. Lysis by NK cells depends on the relatively low expression of HLA class I molecules on MSCs and the expression of activating NK cell receptor ligands. Lysis by autologous NK cells indicates that in vitro expansion induces the immunogenicity of MSCs and, despite all their immune regulatory properties, makes them targets of the immune defence themselves.

\section{Conclusion}

MSCs play a core role in maintaining immune homeostasis in their niche in most, if not all, tissues by interacting with antigen-presenting cells, phagocytic cells, cytotoxic cells, B cells and helper $\mathrm{T}$ cells via soluble and cell membrane-mediated mechanisms. This property is maintained by cells of more differentiated mesenchymal lineages, such as fibroblasts. Under inflammatory conditions MSCs gain additional immunological functions, such as antigen presentation. After culture expansion and administration in humans or animals, MSCs acquire a different function and trigger immunomodulatory responses by their short presence. Their developmental origin and the limited migratory properties of MSCs, which are associated with their role as precursor cells for mesenchymal cells within tissues, show that MSCs are not true immune cells. They are nevertheless omissible for controlled functioning of the immune system and there are promising prospects for the development of MSC-based immune therapy in the near future.

Note: This article is part of a thematic series on Biology and clinical applications of stem cells for autoimmune and musculoskeletal disorders, edited by Christian Jorgensen and Anthony Hollander. Other articles in this series can be found at http://www.biomedcentral.com/series/MSC

\section{Abbreviations}

GFP: green fluorescent protein; HGF: hepatocyte growth factor; IDO: indoleamine 2,3-dioxygenase; IL: interleukin; MHC: major histocompatibility complex; MSC: mesenchymal stromal cell; NK: natural killer; PD-L1: programmed death ligand 1; PGE-2: prostaglandin-E2; TGF- $\beta$ : transforming growth factor $\beta$; TLR: Toll-like receptor; TNF: tumour necrosis factor.

Competing interests

The author declares that he has no competing interests.

Published online: 31 March 2015

\section{References}

1. Friedenstein AJ, Piatetzky II S, Petrakova KV. Osteogenesis in transplants of bone marrow cells. J Embryol Exp Morphol. 1966;16:381-90. 
2. Pittenger MF, Mackay AM, Beck SC, Jaiswal RK, Douglas R, Mosca JD, et al. Multilineage potential of adult human mesenchymal stem cells. Science. 1999;284:143-7.

3. Dominici M, Le Blanc K, Mueller I, Slaper-Cortenbach I, Marini F, Krause D, et al. Minimal criteria for defining multipotent mesenchymal stromal cells. The International Society for Cellular Therapy position statement. Cytotherapy. 2006;8:315-7.

4. Yang ZX, Han ZB, Ji YR, Wang YW, Liang L, Chi Y, et al. CD106 identifies a subpopulation of mesenchymal stem cells with unique immunomodulatory properties. PLoS One. 2013;8:e59354.

5. Russell KC, Phinney DG, Lacey MR, Barrilleaux BL, Meyertholen KE, O'Connor KC. In vitro high-capacity assay to quantify the clonal heterogeneity in trilineage potential of mesenchymal stem cells reveals a complex hierarchy of lineage commitment. Stem Cells. 2010;28:788-98.

6. Wagner W, Feldmann Jr RE, Seckinger A, Maurer MH, Wein F, Blake J, et al. The heterogeneity of human mesenchymal stem cell preparations - evidence from simultaneous analysis of proteomes and transcriptomes. Exp Hematol. 2006:34:536-48.

7. Di Nicola M, Carlo-Stella C, Magni M, Milanesi M, Longoni PD, Matteucci P, et al. Human bone marrow stromal cells suppress T-lymphocyte proliferation induced by cellular or nonspecific mitogenic stimuli. Blood. 2002;99:3838-43.

8. Aggarwal S, Pittenger MF. Human mesenchymal stem cells modulate allogeneic immune cell responses. Blood. 2005;105:1815-22.

9. Spaggiari GM, Capobianco A, Becchetti S, Mingari MC, Moretta L. Mesenchymal stem cell-natural killer cell interactions: evidence that activated NK cells are capable of killing MSCs, whereas MSCs can inhibit IL-2-induced NK-cell proliferation. Blood. 2006;107:1484-90.

10. Corcione A, Benvenuto F, Ferretti E, Giunti D, Cappiello V, Cazzanti F, et al. Human mesenchymal stem cells modulate B-cell functions. Blood. 2006;107:367-72.

11. Nauta AJ, Kruisselbrink AB, Lurvink E, Willemze R, Fibbe WE. Mesenchymal stem cells inhibit generation and function of both CD34 +-derived and monocyte-derived dendritic cells. J Immunol. 2006;177:2080-7.

12. Augello A, Tasso R, Negrini SM, Cancedda R, Pennesi G. Cell therapy using allogeneic bone marrow mesenchymal stem cells prevents tissue damage in collagen-induced arthritis. Arthritis Rheum. 2007:56:1175-86.

13. Zappia E, Casazza S, Pedemonte E, Benvenuto F, Bonanni I, Gerdoni E, et al. Mesenchymal stem cells ameliorate experimental autoimmune encephalomyelitis inducing T-cell anergy. Blood. 2005;106:1755-61.

14. Gonzalez-Rey E, Anderson P, Gonzalez MA, Rico L, Buscher D, Delgado M. Human adult stem cells derived from adipose tissue protect against experimental colitis and sepsis. Gut. 2009;58:929-39.

15. Augello A, Tasso R, Negrini SM, Amateis A, Indiveri F, Cancedda R, et al. Bone marrow mesenchymal progenitor cells inhibit lymphocyte proliferation by activation of the programmed death 1 pathway. Eur J Immunol. 2005;35:1482-90.

16. Gu YZ, Xue Q, Chen YJ, Yu GH, Qing MD, Shen Y, et al. Different roles of PD-L1 and FasL in immunomodulation mediated by human placenta-derived mesenchymal stem cells. Hum Immunol. 2013;74:267-76.

17. Hoogduijn MJ, Popp F, Verbeek R, Masoodi M, Nicolaou A, Baan C, et al. The immunomodulatory properties of mesenchymal stem cells and their use for immunotherapy. Int Immunopharmacol. 2010;10:1496-500.

18. Quaedackers ME, Baan CC, Weimar W, Hoogduijn MJ. Cell contact interaction between adipose-derived stromal cells and allo-activated T lymphocytes. Eur J Immunol. 2009;39:3436-46.

19. Groh ME, Maitra B, Szekely E, Koc ON. Human mesenchymal stem cells require monocyte-mediated activation to suppress alloreactive T cells. Exp Hematol. 2005;33:928-34.

20. Engela AU, Hoogduijn MJ, Boer K, Litjens NH, Betjes MG, Weimar W, et al. Human adipose-tissue derived mesenchymal stem cells induce functional de-novo regulatory T cells with methylated FOXP3 gene DNA. Clin Exp Immunol. 2013;173:343-54

21. Maggini J, Mirkin G, Bognanni I, Holmberg J, Piazzon IM, Nepomnaschy I, et al. Mouse bone marrow-derived mesenchymal stromal cells turn activated macrophages into a regulatory-like profile. PLoS One. 2010;5:e9252.

22. Peng $Y$, Chen $X$, Liu Q, Zhang $X$, Huang K, Liu L, et al. Mesenchymal stromal cells infusions improve refractory chronic graft versus host disease through an increase of CD5+ regulatory B cells producing interleukin 10. Leukemia. 2014. doi:10.1038/leu.2014.225.
23. Munn DH, Mellor AL. Indoleamine 2,3 dioxygenase and metabolic control of immune responses. Trends Immunol. 2013;34:137-43.

24. Regateiro FS, Cobbold SP, Waldmann H. CD73 and adenosine generation in the creation of regulatory microenvironments. Clin Exp Immunol. 2013;171:1-7.

25. Bronte $\mathrm{V}$, Zanovello P. Regulation of immune responses by L-arginine metabolism. Nat Rev Immunol. 2005;5:641-54.

26. Benvenuto F, Ferrari S, Gerdoni E, Gualandi F, Frassoni F, Pistoia V, et al. Human mesenchymal stem cells promote survival of $T$ cells in a quiescent state. Stem Cells. 2007;25:1753-60.

27. Crop MJ, Baan CC, Korevaar SS, ljzermans JN, Weimar W, Hoogduijn MJ. Human adipose tissue-derived mesenchymal stem cells induce explosive T-cell proliferation. Stem Cells Dev. 2010;19:1843-53.

28. Nemoto $Y$, Kanai T, Takahara M, Oshima S, Nakamura T, Okamoto R, et al. Bone marrow-mesenchymal stem cells are a major source of interleukin-7 and sustain colitis by forming the niche for colitogenic CD4 memory T cells. Gut. 2013;62:1142-52.

29. Crop MJ, Baan CC, Korevaar SS, ljzermans JN, Pescatori M, Stubbs AP, et al. Inflammatory conditions affect gene expression and function of human adipose tissue-derived mesenchymal stem cells. Clin Exp Immunol. 2010;162:474-86.

30. Prockop DJ. Concise review: two negative feedback loops place mesenchymal stem/stromal cells at the center of early regulators of inflammation. Stem Cells. 2013;31:2042-6.

31. Krampera M, Cosmi L, Angeli R, Pasini A, Liotta F, Andreini A, et al. Role for interferon-gamma in the immunomodulatory activity of human bone marrow mesenchymal stem cells. Stem Cells. 2006;24:386-98.

32. Ge W, Jiang J, Arp J, Liu W, Garcia B, Wang H. Regulatory T-cell generation and kidney allograft tolerance induced by mesenchymal stem cells associated with indoleamine 2,3-dioxygenase expression. Transplantation. 2010;90:1312-20.

33. Tso GH, Law HK, Tu W, Chan GC, Lau YL. Phagocytosis of apoptotic cells modulates mesenchymal stem cells osteogenic differentiation to enhance IL-17 and RANKL expression on CD4+ T cells. Stem Cells. 2010;28:939-54.

34. Stagg J, Pommey S, Eliopoulos N, Galipeau J. Interferon-gamma-stimulated marrow stromal cells: a new type of nonhematopoietic antigen-presenting cell. Blood. 2006;107:2570-7.

35. Chan JL, Tang KC, Patel AP, Bonilla LM, Pierobon N, Ponzio NM, et al. Antigen-presenting property of mesenchymal stem cells occurs during a narrow window at low levels of interferon-gamma. Blood. 2006;107:4817-24.

36. Romieu-Mourez R, Francois M, Boivin MN, Stagg J, Galipeau J. Regulation of MHC class $\|$ expression and antigen processing in murine and human mesenchymal stromal cells by IFN-gamma, TGF-beta, and cell density. J Immunol. 2007;179:1549-58.

37. Francois M, Romieu-Mourez R, Stock-Martineau S, Boivin MN, Bramson JL, Galipeau J. Mesenchymal stromal cells cross-present soluble exogenous antigens as part of their antigen-presenting cell properties. Blood. 2009;114:2632-8.

38. Geppert TD, Lipsky PE. Antigen presentation by interferon-gamma-treated endothelial cells and fibroblasts: differential ability to function as antigen-presenting cells despite comparable la expression. J Immunol. 1985;135:3750-62.

39. Bagai R, Valujskikh A, Canaday DH, Bailey E, Lalli PN, Harding CV, et al. Mouse endothelial cells cross-present lymphocyte-derived antigen on class I MHC via a TAP1- and proteasome-dependent pathway. J Immunol. 2005;174:7711-5.

40. Kim HS, Shin TH, Yang SR, Seo MS, Kim DJ, Kang SK, et al. Implication of NOD1 and NOD2 for the differentiation of multipotent mesenchymal stem cells derived from human umbilical cord blood. PLoS One. 2010;5:e15369.

41. Hwa Cho H, Bae YC, Jung JS. Role of toll-like receptors on human adipose-derived stromal cells. Stem Cells. 2006;24:2744-52.

42. Raicevic G, Rouas R, Najar M, Stordeur P, Boufker HI, Bron D, et al. Inflammation modifies the pattern and the function of Toll-like receptors expressed by human mesenchymal stromal cells. Hum Immunol. 2010;71:235-44.

43. Liotta F, Angeli R, Cosmi L, Fili L, Manuelli C, Frosali F, et al. Toll-like receptors 3 and 4 are expressed by human bone marrow-derived mesenchymal stem cells and can inhibit their T-cell modulatory activity by impairing Notch signaling. Stem Cells. 2008;26:279-89.

44. Zhao X, Liu D, Gong W, Zhao G, Liu L, Yang L, et al. The toll-like receptor 3 ligand, poly(l:C), improves immunosuppressive function and therapeutic 
effect of mesenchymal stem cells on sepsis via inhibiting MiR-143. Stem Cells. 2014;32:521-33.

45. Kol A, Foutouhi S, Walker NJ, Kong NT, Weimer BC, Borjesson DL. Gastrointestinal microbes interact with canine adipose-derived mesenchymal stem cells in vitro and enhance immunomodulatory functions. Stem Cells Dev. 2014:23:1831-43.

46. Lee JW, Krasnodembskaya A, McKenna DH, Song Y, Abbott J, Matthay MA. Therapeutic effects of human mesenchymal stem cells in ex vivo human lungs injured with live bacteria. Am J Respir Crit Care Med. 2013;187:751-60.

47. Ponte AL, Marais E, Gallay N, Langonne A, Delorme B, Herault O, et al. The in vitro migration capacity of human bone marrow mesenchymal stem cells: comparison of chemokine and growth factor chemotactic activities. Stem Cells. 2007;25:1737-45.

48. Wexler SA, Donaldson C, Denning-Kendall P, Rice C, Bradley B, Hows JM. Adult bone marrow is a rich source of human mesenchymal 'stem' cells but umbilical cord and mobilized adult blood are not. Br J Haematol. 2003;121:368-74.

49. Alm JJ, Koivu HM, Heino TJ, Hentunen TA, Laitinen S, Aro HT. Circulating plastic adherent mesenchymal stem cells in aged hip fracture patients. J Orthop Res. 2010;28:1634-42.

50. Hoogduijn MJ, Verstegen M, Engela AU, Korevaar SS, Roemeling-van Rhijn M, Merino A, et al. No evidence for circulating mesenchymal stem cells in patients with organ injury. Stem Cells Dev. 2014;23:2328-35.

51. Gil-Ortega M, Garidou L, Barreau C, Maumus M, Breasson L, Tavernier G, et al. Native adipose stromal cells egress from adipose tissue in vivo: evidence during lymph node activation. Stem Cells. 2013;31:1309-20.

52. Hoogduijn MJ, Crop MJ, Peeters AM, Korevaar SS, Eijken M, Drabbels JJ, et al. Donor-derived mesenchymal stem cells remain present and functional in the transplanted human heart. Am J Transplant. 2009;9:222-30.

53. Crisan M, Yap S, Casteilla L, Chen CW, Corselli M, Park TS, et al. A perivascular origin for mesenchymal stem cells in multiple human organs. Cell Stem Cell. 2008:3:301-13.

54. Kaukua N, Shahidi MK, Konstantinidou C, Dyachuk V, Kaucka M, Furlan A, et al. Glial origin of mesenchymal stem cells in a tooth model system. Nature. 2014;513:551-4.

55. Hess DC, Abe T, Hill WD, Studdard AM, Carothers J, Masuya M, et al. Hematopoietic origin of microglial and perivascular cells in brain. Exp Neurol. 2004;186:134-44.

56. Ogawa M, LaRue AC, Drake CJ. Hematopoietic origin of fibroblasts/ myofibroblasts: its pathophysiologic implications. Blood. 2006;108:2893-6.

57. Mantovani A, Biswas SK, Galdiero MR, Sica A, Locati M. Macrophage plasticity and polarization in tissue repair and remodelling. J Pathol. 2013;229:176-85.

58. Le Blanc K, Frassoni F, Ball L, Locatelli F, Roelofs $H$, Lewis I, et al. Mesenchymal stem cells for treatment of steroid-resistant, severe, acute graft-versus-host disease: a phase II study. Lancet. 2008:371:1579-86.

59. Tan J, Wu W, Xu X, Liao L, Zheng F, Messinger S, et al. Induction therapy with autologous mesenchymal stem cells in living-related kidney transplants: a randomized controlled trial. JAMA. 2012;307:1169-77.

60. Reinders ME, de Fijter JW, Roelofs H, Bajema IM, de Vries DK, Schaapherder $\mathrm{AF}$, et al. Autologous bone marrow-derived mesenchymal stromal cells for the treatment of allograft rejection after renal transplantation: results of a phase I study. Stem Cells Transl Med. 2013;2:107-11.

61. Duijvestein M, Vos AC, Roelofs $H$, Wildenberg ME, Wendrich BB, Verspaget HW, et al. Autologous bone marrow-derived mesenchymal stromal cell treatment for refractory luminal Crohn's disease: results of a phase I study. Gut. 2010:59:1662-9.

62. Forbes GM, Sturm MJ, Leong RW, Sparrow MP, Segarajasingam D, Cummins AG, et al. A phase 2 study of allogeneic mesenchymal stromal cells for luminal Crohn's disease refractory to biologic therapy. Clin Gastroenterol Hepatol. 2014;12:64-71.

63. Gu F, Wang D, Zhang H, Feng X, Gilkeson GS, Shi S, et al. Allogeneic mesenchymal stem cell transplantation for lupus nephritis patients refractory to conventional therapy. Clin Rheumatol. 2014;33:1611-9.

64. Wang D, Zhang H, Liang J, Li X, Feng X, Wang H, et al. Allogeneic mesenchymal stem cell transplantation in severe and refractory systemic lupus erythematosus: 4 years of experience. Cell Transplant. 2013;22:2267-77.

65. Connick P, Kolappan M, Crawley C, Webber DJ, Patani R, Michell AW, et al. Autologous mesenchymal stem cells for the treatment of secondary progressive multiple sclerosis: an open-label phase 2a proof-of-concept study. Lancet Neurol. 2012;11:150-6.
66. Veronesi F, Giavaresi G, Tschon M, Borsari V, Nicoli Aldini N, Fini M. Clinical use of bone marrow, bone marrow concentrate, and expanded bone marrow mesenchymal stem cells in cartilage disease. Stem Cells Dev. 2013;22:181-92.

67. Wang L, Wang L, Cong X, Liu G, Zhou J, Bai B, et al. Human umbilical cord mesenchymal stem cell therapy for patients with active rheumatoid arthritis: safety and efficacy. Stem Cells Dev. 2013;22:3192-202.

68. Weiss DJ, Casaburi R, Flannery R, LeRoux-Williams M, Tashkin DP. A placebocontrolled, randomized trial of mesenchymal stem cells in COPD. Chest. 2013:143:1590-8.

69. Hoogduijn MJ, Roemeling-van Rhijn M, Engela AU, Korevaar SS, Mensah FK Franquesa $\mathrm{M}$, et al. Mesenchymal stem cells induce an inflammatory response after intravenous infusion. Stem Cells Dev. 2013;22:2825-35.

70. Eggenhofer E, Benseler V, Kroemer A, Popp FC, Geissler EK, Schlitt HJ, et al. Mesenchymal stem cells are short-lived and do not migrate beyond the lungs after intravenous infusion. Front Immunol. 2012;3:297.

71. Perico N, Casiraghi F, Introna M, Gotti E, Todeschini M, Cavinato RA, et al, Autologous mesenchymal stromal cells and kidney transplantation: a pilot study of safety and clinical feasibility. Clin J Am Soc Nephrol. 2011;6:412-22.

72. Melief SM, Schrama E, Brugman MH, Tiemessen MM, Hoogduijn MJ, Fibbe WE, et al. Multipotent stromal cells induce human regulatory T cells through a novel pathway involving skewing of monocytes toward anti-inflammatory macrophages. Stem Cells. 2013;31:1980-91.

73. Roemeling-van Rhijn M, Reinders ME, Franquesa M, Engela AU, Korevaar SS, Roelofs $\mathrm{H}$, et al. Human allogeneic bone marrow and adipose tissue derived mesenchymal stromal cells induce CD8+ cytotoxic T cell reactivity. J Stem Cell Res Ther. 2013;3:004. 